Palimpsesto Vol. 10, № 17 (enero-junio, 2020): 15-23

Universidad de Santiago de Chile, ISSN 0718-5898

\author{
Marcela Croce \\ Universidad de Buenos Aires \\ marcela.croce@gmail.com
}

\title{
Provocaciones al canon: género y crítica acicateados en Las aventuras de la China Iron
}

\section{Provocations to the Canon: Genre and Criticism Spurred In Las aventuras de la China Iron}

\begin{abstract}
Resumen
El artículo aborda Las aventuras de la China Iron (2017), novela de Gabriela Cabezón Cámara en la que se pone en cuestión tanto el género gauchesco como la crítica que lo codificó y lo canonizó. Aunque el libro postula un homenaje al trabajo de Josefina Ludmer El género gauchesco. Un tratado sobre la patria (1988), también recala en otros momentos en que la literatura argentina (e incluso la uruguaya, lo que reconoce el carácter rioplatense de la gauchesca) encara el conjunto. La noción misma de género resulta redefinida $y$, en consecuencia, desestabilizada, al tiempo que se la combina con otras miradas sobre la figura histórica del gaucho, en las que campea la de Sarmiento, homologado a Hernández en su papel común de custodios de la tradición, y la de Borges.
\end{abstract}

Palabras claves: Género gauchesco, Canon literario, Crítica argentina, Tradición, Utopía pampeana.

\begin{abstract}
The article deals with Las aventuras de la China Iron (2017), a novel by Gabriela Cabezón Cámara in which both the gaucho genre and the criticism that codified and canonized it are questioned. Although the book postulates a tribute to the work of Josefina Ludmer El género gauchesco. Un tratado sobre la patria (1988), also stops in other times when Argentine literature (and even Uruguayan, which recognizes the River Plate's character of the gaucho) faces the whole. The very notion of gender is redefined and, consequently, destabilized, while combining it with other views on the historical character of the gaucho, in which dominates Sarmiento's, homologated to Hernández in his common role as custodians of the tradition, and that of Borges.
\end{abstract}

Keywords: Gaucho genre, Literary Canon, Argentine criticism, Tradition, Pampa Utopia. 


\section{Repeticiones, versiones, perversiones}

Una superstición que abruma a la tradición literaria latinoamericana es la cita de Borges. Desmontar su mecanismo es una obligación de honestidad intelectual; admitir su certeza equivale a un reconocimiento indeclinable. Borges insiste en un punto que repugna a la enjundia de ciertas teorías: el de que la ficción es un modo mucho más preciso para establecer relaciones, continuidades y quiebres que el de las esforzadas sistematizaciones emprendidas por la crítica. En tal convicción borgeana arraiga el ejercicio que cumple Gabriela Cabezón Cámara sobre la gauchesca en Las aventuras de la China Iron.

La gauchesca es el centro de la historia de la literatura rioplatense. Género inicial, si se parte de la independencia como momento inaugural de una expresión propia, surge en torno a las guerras de independencia y atraviesa buena parte del siglo XIX para culminar en el Martín Fierro. La condición canónica del poema, justificada con argumentos filológicos, fraguó una firmeza que la ficción se dedicó a desestabilizar, sometiendo el texto a "repeticiones, versiones, perversiones" (Borges, 1974, p.561). En la serie operativa confluyen las explicaciones farragosas, los albures de los personajes que recorren el texto -pasibles de recibir congratulaciones efusivas tanto como juicios morales que ignoran que la ficción es inmune a semejantes normativas-- y los desafíos en que se estrellan las afirmaciones ensoberbecidas que suponen que esa misma actitud las convierte en argumentos irrefutables.

Las aventuras de la China Iron participa de la perversión del Martín Fierro, de la gauchesca, de la figura de autor hernandiana, de los versos en los que se sostiene el relato y, previsiblemente, del género como categoría que no se agota en un conjunto de obras, un puñado de rasgos de estilo o un modo compositivo en el que resuenan los dictados manieristas. El género puesto en cuestión es un embate contra el canon y una desestabilización del archivo ufanista por cuya intervención se desbaratan las presuntas seguridades de la tradición. En esta versión que repite algunos lugares comunes solamente para evidenciar su insustancialidad es la perversión la que se entroniza para remontar la dimensión creativa y productiva de un espacio que, en su cerrazón suficiente, amenaza con impregnar a su sucesión.

\section{Ensayo sobre el don}

Sería desolador comenzar por una frase en la que se filtra la pobreza retórica de la política argentina contemporánea sin conjurarla de alguna manera. Por eso, la comprobación que insiste en el primer capítulo de Las aventuras de la China Iron, la que sostiene que "la miseria alienta la grieta, la talla" (Cabezón Cámara, 2018, p.11), reclama apartarse de las connotaciones que le adjudica la urgencia del momento. Sería absurdo ignorar que esa grieta atraviesa la historia y la literatura argentina, como si el Zanjón de Alsina fuera una metáfora más ajustada que la de "los dos ojos del romanticismo" (Viñas, 1964). Pero el Zanjón de Alsina, ni falta hace decirlo, no es solamente metáfora sino herida espacial, cicatriz concreta, división radical que Cabezón Cámara postula no exclusivamente en las consecuencias políticas que promueve sino también en la bifurcación del canon que acicatea.

En "ese río que se comía las orillas" (Cabezón Cámara, p.11) durante el trayecto polvoroso que cumple la China, lo primero que se desestabiliza es el canon fluvial que postula la literatura argentina, enorgullecido con el afán virreinal que le atribuía Nicolás Rosa en El arte del 
olvido (Rosa, 2004). El río de la Plata que retoma Saer en El río sin orillas, y las aguas turbias dentro de cuyo régimen Perlongher (2013) alucina en el neobarroso un Caribe transplatino, arrastran un desafío al Paraná del cual se ufanaba el intelectual iluminista que era Lavardén. Cabezón Cámara, tironeada acaso entre adhesiones que no llegan a la fidelidad, convierte el río sin orillas en la pampa ilimitada, la turbiedad en brillo apenas opacado por la polvareda tenaz y la fusión del espacio fluido, y la llanura persistente en una variante de la "corriente zaina" de prosapia borgeana. El recorrido por la literatura argentina conduce del romanticismo a la gauchesca y recala en la China cautiva como síntesis del siglo XIX local. Una literatura alternativa: eso es lo primero que despunta en Las aventuras de la China Iron. No ya una gauchesca femenina como la que ocupaba las provocaciones de Osvaldo Lamborghini (1980) sino una gauchesca donde el género -en todas sus acepciones-- resulte, a la manera de Butler (2007), puesto en disputa.

"Ensayo sobre el don" se titula este segmento inicial, que recupera a Marcel Mauss. En su propuesta antropológica, que recibió escasa atención inicial (Giobellina Brumana, 2009), se definen tres obligaciones: dar, recibir, devolver. Sin voluntad de aplicar mecánicamente el modelo, entiendo que la novela de Cabezón Cámara cumple ese circuito en relación con el canon. Dado un texto -el Martín Fierro-- que representa la condensación y la culminación de un género -la gauchesca--, Las aventuras de la China Iron lo recibe y lo devuelve tergiversado. A la indagación de los pormenores de ese proceso dedicaré esta presentación. Sin embargo, me adelanto al planteo del esquema general anotando un par de suspicacias. Una es que la gauchesca no ha funcionado en el orden novelístico. Allí está para demostrarlo Don Segundo Sombra desde la crítica irreverente y feroz que le dedica Borges en su cuento "El Evangelio según Marcos", donde Espinosa lee la obra de Güiraldes ante el capataz Gutre y su familia; pero el hombre había sido tropero y no podían interesarle las andanzas de otro, por añadidura magnificadas de un modo que irrita la verosimilitud. La segunda sospecha indica que el género canónico de la literatura argentina no consiste únicamente en los textos que componen su repertorio sino también -y sobre todo- en la crítica que se ocupa de canonizarlo.

El canon, como la biología que descalabra Butler, abandona las implicaciones del presumido destino para resolverse en trabajosa construcción. En ella confluyen tácitamente la voluntad de Lugones de elevar al Martín Fierro a epopeya argentina y la decisión de Rojas de instalar la obra como épica local, copiosamente informado por la filología. Pero también, en términos explícitos, acuden el Borges de "El fin" y la "Biografía de Tadeo Isidoro Cruz" y, más próxima y acaso inscripta como interlocutora ideal, Josefina Ludmer, avalada por El género gauchesco. Un tratado sobre la patria, escrito treinta años antes que la China Iron. Propondré, entonces, que el momento en que Fierro le pide perdón a la China replica (reemplaza) imaginariamente el instante en que Cabezón Cámara se reconoce en el gaucho que ha suspendido la rebelión por la creación, el ajusticiamiento de los pares por el diseño de indumentaria. En esa escena increíble la escritora se coloca frente a Josefina (la China) Ludmer para solicitar una indulgencia por esta versión de la gauchesca con que desafía --sin lamento-- el trabajo de la crítica, aunque manteniéndose dentro de la fórmula del "uso letrado de la cultura popular" (Ludmer, 1988). La cinta patria repujada de lazos y nudos en El género gauchesco se riza en la China Iron en las trenzas de Fierro. Es entonces cuando las certezas se bambolean y las convicciones se soliviantan: en la cabeza sometida a los furores de la peluquería, la capilaridad impuesta se asoma a lo siniestro, del mismo modo que en los bucles de la Venus de Botticelli reconocía Aby Warburg (2015) la amenaza paralizante de la Cabeza de Medusa. 
La desestabilización de los signos de la gauchesca en la novela donde, entre otras transgresiones, la sangre como señal de muerte muta a manifestación sensible -así lo revelan las venas de Elizabeth que interrumpen su cutis transparente--, se alterna con la agudización de los conflictos expuestos en el género. De este modo, el compañerismo es apenas reconocimiento de un desamparo común, fomentado por la pampa cerril que desbarata toda morfología y conspira contra la posibilidad de localización. En el reflejo de intemperies simétricas, la de la inglesa -en verdad escocesa-- que ha perdido a su marido en el sur inclemente, y la de la China que escapa de una tapera en la que no conoció más que violencia y desprecio, la verdad encuentra un patrón de medida en la experiencia corporal. El estrechamiento de vínculos exige acotar el espacio, circunscribir la inmensidad. Y el modo de hacerlo es mediante una carreta provista de sábanas de seda y vajilla de porcelana. La carreta opera a modo de cronotopo (Bajtín, 1990), en tanto disparador narrativo, y como "forma simple" (Jolles, 1969) de tránsito espacial, cuya estirpe literaria tributa simultáneamente al rejunte de desechos que exhibe Madre Coraje en la alegoría brechtiana y a la reunión prostibularia que fomenta Enrique Amorim en su novela La carreta, en la que se vislumbra una road movie rudimentaria bajo el proxenetismo rural de un gaucho decadente que responde al apodo de Matacabayo (Amorim, 1988).

$\mathrm{Al}$ amparo de la carreta que mitiga la intemperie proliferan las equivalencias. El "personaje histórico fundamental" que Martínez Estrada (1948) reconocía en la vaca destella en la luz lamedora de la pampa. El "centauro" en que se amotinó la leyenda gauchesca define a los indios, cuyos "heroicos esqueletos" adquieren apostura de fósiles interespecies en el abandono que los rodea (Cabezón Cámara, p.35). Dentro de la armazón móvil de cueros y madera, el lenguaje que traman Liz y la China se reduce al significante -lo que contribuye a la conmoción de los sentidos excitados por los olores del sándalo y el láudano y el sabor del curry- y recorta el juego de equivalencias lingüísticas a pura resonancia. Una sucesión de sonidos sin eco: tal es la modesta teoría de la traducción pampeana que encara la China Iron. Un almacén de la Compañía de las Indias: así se sintetiza el dispendioso paso de Liz por un territorio al que impregna de Inglaterra, tanto cuando recuerda a su padre a la manera de un Turner fascinado por inmensidades borrascosas, como cuando le cede a la China unos botines victorianos que arrastran excesiva familiaridad con los guantes que Mansilla emplea a modo de estrategia de seducción entre los ranqueles.

De semejante transculturación no cabe esperar sosiego sino el paso adicional hacia el otro lado que implica el travestismo: el vestido y las enaguas se truecan por las bombachas y camisas del inglés ausente, la trenza se desintegra en un corte al ras y la China Josephine Star Iron se asimila al "good boy" que merece un beso en la boca más próximo al "pecado internacional" que a la "costumbre inglesa" (p.39). El don toma entonces visos de trueque y, bajo el trastocamiento general que acarrea el cambio, no hay sentido del género que no resulte revolucionado: el género identitario, el género literario, la tela de la ropa masculina que se presta menos a cubrir la desnudez que a fraguar una apariencia deseada. El cambio genérico se esparce por el relato: la gauchesca se metamorfosea en novela de aventuras y el baquiano Rosario, al sumarse al extraño cortejo compuesto por Liz, la China y el perro Estreya, resulta sometido a una multiplicación nominal cuyas variantes son todas femeninas: Rosa para la China, Rose para Liz.

Una teoría de la traducción y del género, expuesta en forma de relato en tránsito que desafía las previsiones de la gauchesca y suprime la versión de la desventura empecinada que es el lamento, reclama una teoría de la literatura. Las aventuras de la China Iron, a través de un recorrido libre de itinerario y sostenido apenas en la esperanza de Liz de encontrar al inglés cautivo y en la de Josefina de renunciar definitivamente a la vida en la tapera, comienza a diseñar 
una ficción teórica. En su enunciación, sin ignorar el papel de los viajeros ingleses en el origen de la literatura argentina -al fin y al cabo, es el punto de partida de Muerte y transfiguración de Martín Fierro-, la escena primordial es la de la formación de la lectora. Los dones de la inglesa no se agotan en el paso levistraussiano de lo crudo a lo cocido ni en las concesiones a las maneras de mesa; tampoco en las veleidades de la moda que campean en accesorios impropios -el botín victoriano hundido en la bosta--, sino que se extienden a la cesión de los bienes culturales iniciada en el intercambio alfabético para establecer el diálogo.

Liz lee Frankenstein y provoca en la China un sueño de dragones próximo al de las ovejas eléctricas: en el gótico pampeano que resulta del impacto del texto, los dragones pueden ser "animales de la ciencia eléctrica inglesa" (p.59), inclusive cuando tan momentáneo asomo a la ciencia-ficción quede sepultado repentinamente por el realismo social que alienta en Oliver Twist. Los viajeros ingleses se desentienden de su impronta colonial en esta escena de lectura en la cual el trastorno del canon argentino redunda en acceso ingenuo al canon inglés, siempre sobresaturado de interpretaciones, invariablemente nimbado de su propia crítica. En la China de alfabetización veloz y voraz se reproduce el plan de Raymond Williams (1997) como profesor en las escuelas de clase obrera inglesa, empeñado en leer los clásicos británicos con un público inmune a las canonizaciones y proclive a una estructura de sentimiento que la novela de Cabezón Cámara recupera al instalar el relato como don amoroso.

\section{La aventura consta en un libro insigne}

La novela continúa la propuesta de Ludmer y admite que el don tiene dos caras: la de la cesión de la voz -el autor que presta su nombre para la elocución del gaucho-- y la del patrón, el dueño (el "don") de la estancia. Si la primera parte de Las aventuras de la China Iron se desarrolla en el desierto, donde los vestigios de La cautiva echeverriana se filtran en un espacio de uniformidad sediciosa, la segunda parte transcurre en el fortín, bajo el mando del coronel Hernández que desafía la versión biográfica para encarnar el discurso sarmientino. "La aventura consta en un libro insigne", deslizaba Borges para aludir al Martín Fierro; en el texto de Cabezón Cámara, el libro insigne que informa a Hernández es el Facundo. Los relampagueos pampeanos evidencian que la "civilización" es un proceso transmutativo de adquisición de identidades sucesivas y transitorias.

En el marco del entrenamiento al cual el coronel somete a los gauchos acude el recitado del Martín Fierro, pero al cabo de dos estrofas reproducidas con exactitud sobreviene una intervención -adicional, en el marco novelístico-- sobre el texto: en tales versos, la rima trastabilla y los consejos morales de Fierro redundan en ímpetus patrióticos y dictados del progreso. El Martín Fierro se desliza subrepticiamente al Santos Vega de Rafael Obligado, con sus afanes de pampa alambrada y ganadería próspera. La impostura se vuelve transparente: es apenas la "demostración gauchesca" (Cabezón Cámara, p.101) que el coronel exige a sus subordinados en el sucedáneo de conscripción que despliega la ambigüedad del término "instrucción": la preparación militar y la contracción alfabetizadora coinciden y exigen la síntesis que es la Instrucción del estanciero hernandiana. La versión del Padre Nuestro encarada por el "don" orilla entonces la herejía, allí donde los aspectos celestiales rebalsan de tenor pedestre hasta la frase "hacé tu reino en la estancia" (p.102). 
La justificación mayor de la opresiva civilización hernandiana radica en que "hubo que conquistarle una tierra a la patria" (p.105). El desierto de la primera parte de la China Iron retorna ahora en su versión prosaica: no se trata de la resonancia poética de "la hora/ en que el sol la cresta dora/ de los Andes" sino de la dimensión histórica que repone Tulio Halperin Donghi (1980) cuando reclama Una nación para el desierto argentino. Pero como en la novela de Cabezón Cámara nada permanece estable y el desplazamiento se consagra como ley de toda referencia, detrás de las especulaciones progresistas de Halperin lo que se alza es un interrogante perturbador que queda asentado en el libro que le dedica al autor de Martín Fierro, titulado José Hernández y sus mundos (1985): ¿cómo es posible que un sujeto carente de todo relieve escriba de pronto una obra genial?

Las aventuras de la China Iron ofrece la respuesta más verosímil a semejante inquietud: quien escribe el Martín Fierro es el propio Martín Fierro, a quien Hernández ha expropiado sus versos. La única obra hernandiana comprobable es la Instrucción del estanciero, libro en el que se mantiene del lado del "don", es decir, de los señores. En la pedagogía violenta que aplica para poner en práctica semejante catecismo civilizatorio, en la fascinación con que recibe a la inglesa pelirroja y en la respuesta consecuente que obtiene de ella -a quien las alfombras y los cuadros ponen "turgente" (p.88)--, la Instrucción del estanciero reviste tintes conradianos y se lee como Una avanzada del progreso, lo que completa la formación lectora de Josefina que, como Conrad, advierte las ventajas que acarrea la adscripción inglesa.

Falta, es cierto, el inglés más insoslayable a los fines canónicos, y nuevamente es la dimensión sarmientina de Hernández la que lo convoca. El furor hernandiano desplegado en la Vida del Chacho se apacigua en la adhesión al Facundo, cuya invocación a la "sombra terrible" de raigambre shakespereana habilita otro sobrevuelo del sanjuanino egotista. Es el despliegue autobiográfico de Sarmiento el que se impone en la proclama ufanista de Hernández: "yo camino de hierro, yo fuerza de vapor, yo economía de las pampas, yo simiente de civilización y progreso en esta tierra feraz y bruta, nunca antes arada" (p.107). Así como Cruz deja de ser necesario en el Martín Fierro porque su propósito no era otro que salvar al desertor, como demostró Borges, el gaucho pendenciero exige ser reconvertido a las necesidades de una patria pujante. Los amancebados con sus madres, de cuya cruza resultan "unos Habsburgos retacones y negros" (p.108), son educados por "una de las gringuitas de Sarmiento" (p.108) que, al ser violada, vengó el vejamen con una ferocidad que no renunció al estaqueo ni a la carne humana asada. Los mellizos que parió revirtieron la deformidad agauchada sumando a los rasgos caucásicos de la madre un idéntico odio al progenitor abrupto y deseos simétricos de ser cowboys en Minneapolis.

Cuando la China reconoce los versos de Fierro en la recitación impostada que les depara Hernández comprende que el coronel no solamente le robó a esa "bestia inspirada" (p.119) que fue su marido sino también a ella. La estancia ratifica la revelación de la propiedad, y lo que era donación en "El desierto" se torna ahora posesión del "don". Ni siquiera las escenas amatorias de Josefina y Liz, cuyas conductas quedan excesivamente lastradas de puro instinto como para acceder al erotismo, aplacan la convicción expropiatoria que late en la fórmula "uso letrado de la cultura popular" (Ludmer, 1988). Tampoco la revelación de la homosexualidad de Fierro mitiga el daño: el apodo de "Gallo" que Hernández le dedica (p.120) parece más propicio para introducirlo en la serie gauchesca pródiga en aves de corral -Aniceto el Gallo, Anastasio el Pollo- que para descastarlo desde la cartilla machista que enarbola el coronel en su pretensión de acceder a Liz.

Es entonces cuando cobra relevancia el nombre del fortín "Las Hortensias", que apela a la designación felisbertiana con vistas a solazarse en la perversión más funesta para los planes 
productivos del coronel: la de la fiesta que culmina en desborde. Si en torno al erotismo frustrado era factible intuir a Bataille (1997), en la celebración desbocada resulta imposible eludirlo. El derroche es la donación desorbitada que, en la estancia comandada momentáneamente por la inglesa, desata una bacanal de ponche y danzas folklóricas, en la cual las figuras del baile despliegan una genitalidad encabritada. Al cabo del desenfreno orgiástico, los gauchos volverán al sometimiento, el coronel procurará disimular la transgresión y la improvisada trinidad de Liz, Josefina y Rosario -secundada por Estreya- volverá a la libertad del "mundo carreta" (p.129) que, tras la experiencia estanciera, avanza hacia la utopía anarquista.

\section{Memorias de la otredad}

"Nos comimos un charqui al chutney" (p.140): no hay proclama más rotunda de la transculturación manifiesta en la travesía pampeana que esa frase gastronómica. El almacén de la Compañía de Indias que destila la carreta refina los sentidos, de modo que el erotismo desaforado de la estancia comienza a apaciguarse a medida que los personajes se asoman a la utopía indígena. Las precisiones carnales nimbadas de lenguaje brutal se despojan de toda aspereza para asociarse a una síntesis casi poética: "igual de sedosa y relumbrante y negra y azulada fue la noche para mí: para nosotras dos" (p.143). Idéntica ebullición libre de atolondramientos muestra la naturaleza en esa antesala del sitio fantástico en que recala la carreta.

El final de Las aventuras de la China Iron convierte al desierto en utopía, de modo que el pretendido vacío de la primera parte -todavía arraigado en la representación gauchesca de la pampa-- resulta llenado con la imaginación. El espacio inconcebible que se asocia al horror del salvajismo es el locus al que se logra acceder tras la pormenorizada educación sensorial que avanza por aromas, sabores y excesos corporales. Por eso la percepción de los indios se logra por proximidad sensual: "Los escuchamos primero y los olimos. Cantaban, también, y comían asado" (p.150). La atracción indígena por las cautivas blancas en que se solazó el romanticismo argentino se revierte en el erotismo que despiertan los indios, sin distinción de sexo ni de género, como si la horizontalidad de la utopía tradujera la llanura en uniformidad reacia a jerarquías y distinciones.

La confusión de géneros en que incurre la lengua del indio abandona la presunta reproducción de los tropiezos orales del pampa en que insistían los letrados decimonónicos para erigirse en manifiesto transgenérico. Lo que parece error morfológico es reconocimiento de la multiplicidad genérica que resuena en la frase de acogida: "Bienvenida a nuestra fiesta, mi querida muchacho inglés" (p.151). La ratificación de que tales usos son voluntarios radica en que los propios indios que trastornan los géneros gramaticales son capaces de hablar "en un castellano prístino" (p.151); acaso el mismo que, con inflexiones medievales, maneja la Virgen Cabeza de la novela homónima de Cabezón Cámara. Las aventuras de la China Iron confirma así su opción por la entonación del desafío en la alternativa entre desafío y lamento que conceptualiza Ludmer. Y, en pos de perfilar un estilo que vuelva reconocibles los modos gauchos pero se resista a plegarse al canon gauchesco, la elección de los títulos de cada capítulo con una frase seleccionada del conjunto narrativo replica la práctica que define los episodios de esa provocación irónica al género que representa Inodoro Pereyra.

Reitero, en la vertiente butleriana: ni canon ni biología son destino. Admitido este principio, el aparente indio de trenzas largas y túnica de plumas rosas no puede ser sino Martín 
Fierro. En su figura de "china disfrazada de flamenco" (p.157) se estrellan Aniceto el Gallo y Anastasio el Pollo --y todas las insinuaciones machistas que desgranaba Hernández-- para definirse por un ave exótica menos propicia a la sequedad polvorienta de la pampa que a la humedad de bañados y esteros. La disociación entre el ave y su hábitat permite la introducción de un capítulo en verso que no cesa de trastabillar: mientras los verbos aparecen normalizados respecto de las eses abusivas que campean en la gauchesca, la metátesis de "naides" se mantiene como huella incólume del dialecto aludido. En tales renglones, fracasados como poesía pero reveladores como relato, se impone la sorpresa: Fierro mató a Raúl, el enamorado de la China, porque "siempre tuve miedo/ De que cuente el entrevero/ Del tiempo que fue mi amao" (p.159). Establecer las diferencias entre este impromptu verbal y el canon gauchesco es ocioso. Baste retener de semejante transmutación del Martín Fierro la aparición de Cruz que, sin suspender la función salvadora que reviste en el poema y que recalca el cuento borgeano, añade el homoerotismo maternal y el ejercicio homosexual que trasunta la única felicidad de la vida del gaucho, quebrada con la muerte del compañero.

Lo que comenzó en la fiesta disruptiva del fortín se expande a extremismo del ardor en la pampa desregulada de los indios libertarios. La utopía centraliza la naturaleza al tiempo que le asesta un golpe de gracia al naturalismo; la disolución del sujeto en la comunidad suprime la novela de aventuras que depende de la fijación de experiencias sobre un individuo; la designación "Iñchiñ" evidencia la incapacidad del español para dar cuenta tanto de la fonética vernácula como de los matices de la población y las variantes de la geografía sudamericana que abunda en ríos "de crecidas feroces y silenciosas" (p.174) y en la cual medran los hongos alucinógenos de cuyo consumo "se sale otro" (p.180), como en las ceremonias del Santo Daime que Perlongher relató con una prosa erizada de estrías deleuzianas para luego ritualizar en auto sacramental. En los ríos que promueven la presencia del flamenco y que desmienten la superstición letrada del desierto pampeano se desplazan Rosa, Liz y José remando, suplantada la carreta por el wampo, "tejidos los tres" (p.182) en una trama que pervierte la cinta patria del tratado de Ludmer en un improvisado tapiz indio que certifica la unión directa.

El régimen fluvial que me permitió iniciar este merodeo por el canon desestabilizado vuelve a concurrir en el cierre. Contra las previsiones mercantiles de la Oda de Lavardén, "nuestra nación [va] migrando lentamente por el Paraná" (p.184). En lugar del progreso comercial, Las aventuras de la China Iron adhiere a la sustracción final: "Sabemos irnos como si nos tragara la nada: imagínense un pueblo que se esfuma [...] y se va desvaneciendo como un fantasma" (p.185, itálicas mías). El gesto es más propicio a la literatura de mar que a la de río, esa literatura inglesa que participa de la instrucción de la China pero no de su contexto. Se trata de una nueva incursión en la marginalidad de la literatura argentina que, luego de atravesar la pampa y espolear el canon, se resuelve por la fluidez del río y repugna la fijación territorial propia de exigencias identitarias firmes y definitivas. La gauchesca femenina que pretendía Lamborghini resulta una opción tibia superada por esta gauchesca paradójicamente transgénero, donde lo pampeano resigna sus privilegios al ser sometido a la utopía y la utopía renuncia a su radicación para convertirse en un flujo de tránsitos, discontinuidades y, quién sabe, naufragios. 


\section{Referencias Bibliográficas}

Amorim, E. (1988). La carreta. México: Colección Archivos-Fondo de Cultura Económica. Bajtín, M. (1990). Estética de la creación verbal. México: Siglo XXI.

Bataille, G. (1997). El erotismo. Barcelona: Tusquets. . (2009). La parte maldita. Buenos Aires: Las Cuarenta.

Borges, J. L. (1974). “El fin” y "Biografía de Tadeo Isidoro Cruz”, en Obras completas. Buenos Aires: Emecé.

. (1970). "El Evangelio según Marcos", en El informe de Brodie. Buenos Aires: Emecé.

Butler, J. (2007). El género en disputa. Barcelona: Paidós.

Cabezón Cámara, G. (2018). Las aventuras de la China Iron. Buenos Aires: Literatura Random House.

Giobellina Brumana, F. (2009). Estudio preliminar: "El don del ensayo", en Marcel Mauss. Ensayo sobre el don. Buenos Aires: Katz (7-60).

Halperin Donghi, T. (1985). José Hernández y sus mundos. Buenos Aires: Sudamericana. . (1980). Una nación para el desierto argentino. Buenos Aires: Centro Editor de América Latina.

Jolles, A. (1969). Formes simples. Paris: Seuil.

Lamborghini, O. (1980). "Sobre la parodia", en Lecturas críticas n 1. Buenos Aires.

Ludmer, J. (1988). El género gauchesco. Un tratado sobre la patria. Buenos Aires:

Sudamericana.

Martínez Estrada, E. (1948). Muerte y transfiguración de Martín Fierro. México: Fondo de Cultura Económica.

Mauss, M. (2009). Ensayo sobre el don. Buenos Aires: Katz.

Perlongher, N. (2013). Prosa plebeya. Selección y prólogo de Christian Ferrer y Osvaldo Baigorria. Buenos Aires: Excursiones.

Rosa, N. (2004). El arte del olvido y tres ensayos sobre mujeres. Rosario: Beatriz Viterbo.

Viñas, D. (1964). Literatura argentina y realidad política. Buenos Aires: Jorge Álvarez.

Warburg, A. (2015). La pervivencia de las imágenes. Buenos Aires: miluno.

Williams, R. (1997). La política del modernismo. Buenos Aires: Manantial. 